\title{
Modular multilevel converter (MMC) based STATCOM with vector control and virtual impedance voltage compensations
}

\author{
A. U. Lawan', Haider A.F. Almurib ${ }^{2}$, Jeen G. Khor ${ }^{3}$ \\ 1,2,3 Department of Electrical \& Electronic Engineering, University of Nottingham, Malaysia \\ ${ }^{1}$ Department of Electrical Engineering, Husseini Adamu Federal Polytechnic, Nigeria
}

\begin{tabular}{l} 
Article Info \\
\hline Article history: \\
Received Oct 8, 2018 \\
Revised Nov 20, 2018 \\
Accepted May 29, 2019 \\
\hline
\end{tabular}

Keywords:

Multilevel converter

STATCOM

PI controller

Voltage compensation

\begin{abstract}
This paper presents modular multilevel converter (MMC) with circulating current control which provides an improved balanced capacitors voltages. The control is achieved by employing compensation techniques in the external and internal controls of the MMC based static compensator (STATCOM). Performance variations arise during STATCOM non-ideal operation with grid externally and during capacitors voltage transients due to charging and discharging within the MMC that result in the emergence of a voltage disturbance. The proportional integral (PI) controller is usually employed in the external and internal controls for a fast response and reactive current control. In this paper, the performance of the PI controller is improved using voltage compensation in the external control and virtual impedance in the capacitor voltage control within a five-level MMC. The proposed control minimizes the variations in the STATCOM operations with the grid and within the MMC to provide an enhanced overall system response.

Copyright (C) 2019 Institute of Advanced Engineering and Science. All rights reserved.
\end{abstract}

\section{Corresponding Author:}

Abdurrahman Umar Lawan,

Departement of Electrical and Computer Engineering,

University of Nottingham, Malaysia Campus,

43500 Semenyih. Malaysia.

Email:kecx4aua@nottingham.edu.my

\section{INTRODUCTION}

Multilevel inverter topologies are widely accepted as one of the most recent technological advances in power electronic industries. Their uses are mostly in the area of higher-voltage power applications such as flexible A.C transmission systems (FACTS) applications, and large power electric drives. These applications are possible due to multilevel converters' balanced and distributed voltage stresses that are shared among the switches. Power quality (PQ) enhancement in the power system distribution has been attained using multilevel STATCOMs [1-4]. There are many time domain based control schemes such as direct and indirect control, power synchronization, and direct-quadrature(d-q) vector control methods applied to the multilevel STATCOM for the power quality enhancement [5-8]. Among these schemes, the most commonly employed are the direct control and the d-q vector control methods, employed mostly for reactive power (VAR) compensations in STATCOM applications[5, 6]. STATCOM applications for VAR compensation and stability studies have been employed based on different controls and modulation schemes [9-11].

Generally, there is trade-off between the modulation schemes, the switching frequency, transient response and the use of filters for STATCOM VAR compensation. The transient response can improve with high switching frequency, but at the expense of high loss and harmonics. Since filters such as inductors and capacitors are inversely proportional to switching frequency, the high-switching frequency allows the use of small filters and results in more margin gain to be used to control the VAR at the moderate frequencies. This control action will help in improving the transients. Filters do reduce harmonics in the system. However, the 
use of filters in VAR application results in the increase of the system response delay [12]. For instance, a selective harmonic modulation, which is a low-frequency modulation control was employed in [13]. This was carried out using a proportional (P) controller to achieve VAR compensation in an unbalanced system.

Although the control used a second-order filter to suppress the effects of distortions, the proposed control still offers a fast response by reaching its steady-state within 5 cyles. However, this compensation was achieved with a higher-switching frequency (i.e $10 \mathrm{kHz}$ ) to attain the desired current control bandwidth. Furthermore, when the P-control action was compared with the proportional integral (PI) control in the system, the distortion in the current was marginally reduced. Another control using the carrier shifted pulse width mudlauation (CSPWM) was carried out in [14]. This control was for a VAR compensation in a multilevel STATCOM under different operating conditions. The control performance was evaluated from capacitive mode to inductive mode. The author claimed to have reduced the switching frequency by the use of a new reactive current reference, the control was achieved using P-controller based decoupled current control. However, there was a delay in the system at the start up of the control, which reached its steady-state after approximately 10 cycles. Though at the transition, the transient response was fast. A well-tuned PIcontroller could yield response with zero or minimum steady state error within a small rise time. However, PI controllers may have some drawbacks which include high settling time and overshoots [9, 15]. It has also been reported that PI controllers have poor transients compared to other controllers such as hysteresis and ramp time controllers in voltage source inverter (VSI) STATCOMs [15]. For example in [16], PI control was employed for STATCOM voltage regulations, but oscillation has occurred in the response and produced poor transients though there was a minimal steady-state error in the command tracking. Alternatively, the simplest approach is to use carrier shifted pulse width modulation (CSPWM) which has a moderate switching frequency feature and a few control complications. This could be employed with proportional controllers for a decreased rise time and steady-state error [14]. However, this would be at the expense of an increased over shoot compared to proportional integral (PI) controllers. This is possible due to the facts that as the Pcontroller pushes harder for a given level of an error, it forces the control to respond quickly but also to overshoot more. For an MMC inverter specifically, increasing the stacked cells increases the switching frequency and voltage ripples. Depending on a number of the levels, this would, in turn, increase the control complications such as the capacitors voltage balancing and voltage disturbances which produce harmonic ripples. However, the switching frequency and voltage ripples issues could be resolved by the use of fundamental (low) frequency techniques such as selective harmonic elimination (SHE) or optimized switching technique, but with an increased control complexity such as the modulation angle calculation plus the inherent difficult implementation of a low switching technique [17].

Another challenge in the MMC is the stacked cells capacitor voltage balancing. If the power losses were identical in all the different H-bridge cells, the losses could be shared uniformly among the cells; thus, the active and reactive power would be distributed equally within the MMC. However, because of the mismatch among the components especially the cell capacitors, and the charging and discharging during switching, the cells would not behave identically, hence result in different losses. This leads to voltage imbalances and harmonic distortions. To avoid this, balancing control schemes could be employed [18]. This has been further highlighted as part of the MMC design and operational constraints which contribute to the capacitor voltage ripple, current ripple, and power loss depending on the capacitor and inductor sizes [19].

The balancing control has effects on the power quality. The voltage imbalance that could arise due to poor voltage balancing control injects harmonic currents into the system [18]. Haw et al. [14] and Kaw et al. [20] have studied the voltage support but did not consider the issue of cell balancing voltage disturbance. This disturbance could contribute to the emergence of the voltage difference between the arithmetical average dc capacitor voltage of all the phases, and the total arithmetical mean dc capacitor voltage from each phase. This consideration could have improved the system performance in terms of the active power sharing between the STATCOM and the grid, and improve system stability. However, balancing control adds complications by adding many controllers mostly PI-controllers in the modulation control. This addition of the controllers in the system puts more pressure on the digital implementation; thus, requiring heavy digital signal processing. Huang et al. [21] proposed control using a repetitive controller to eliminate harmonic current based on the CSPWM. The transient was good, however, the practical implementation of repetitive controller requires complicated stability and design in choosing the appropriate low pass filters or comb filters needed to stabilize the controller. Liao et al. in [22] have improved the balancing control but the issue of circulating current ripples and voltage ripples remain. Lives et al. [23] and Tu et al. [24] have studied the circulating current that could be employed to achieve capacitors voltage balancing, and suppress the circulating current by increasing the inductance of the arm of the MMC. However, the voltage across the inductor arm deteriorates the performance of the $\mathrm{MMC}$ as the inductor consumes part of the amount of the reactive power (VAR), and the cost increase due to the increase of the arm inductor. Bergna et al. [25] have proposed energy-based balancing control, using a model which controls the voltage sum and voltage

Int J Pow Elec \& Dri Syst Vol. 10, No. 4, Dec 2019: 1833 - 1851 
difference between the upper arm capacitors and their corresponding lower arm capacitors in the three-phase MMC. The control was with respect to the energy stored in the arms.

In this paper, for an MMC with stacked cells, limited switching frequency employed using CSPWM as in [21], would provide a sufficient control bandwidth which would improve the response and provide a good damping effect. Furthermore, the increased no. of the stacked cells voltage variation in the multilevel will be used to improve the stability at both grid-interface level and within the MMC internal control. Unlike in [21], where a large stability analysis due to the repetitive-controller parameter selection was involved, a simple virtual impedance based PI control with some qualities of a low pass filter such as harmonics reduction would be employed. This control, unlike in Begna et al. [25], could be applied in both single-phase or three-phase system, and still, uses the decoupled control. Furthermore, the use of CSPWM with a high integral gain would eliminate the steady state error [26] when employed in the proposed control scheme.

Figure 1 depicts the three-phase MMC based STATCOM system. If and Vc re the MMC based STATCOM three-phase output current and voltage respectively. Vf is the grid voltage at the point of coupling (PCC). Applying Kirchhoff's principle on any leg/phase in the three-phase system with respect to node $\mathrm{n}$, the mathematical relationship between the per phase output current $i_{k}$, the lower and upper arm currents $\left(i_{k p}\right.$ and $\left.i_{k n}\right)$, and the circulating current $i_{c i r k}$ are given by:

$$
\begin{aligned}
& i_{k}=i_{k p}-i_{k n} \\
& i_{\text {cirk }}=\frac{1}{2}\left(i_{k p}+i_{k n}\right)
\end{aligned}
$$

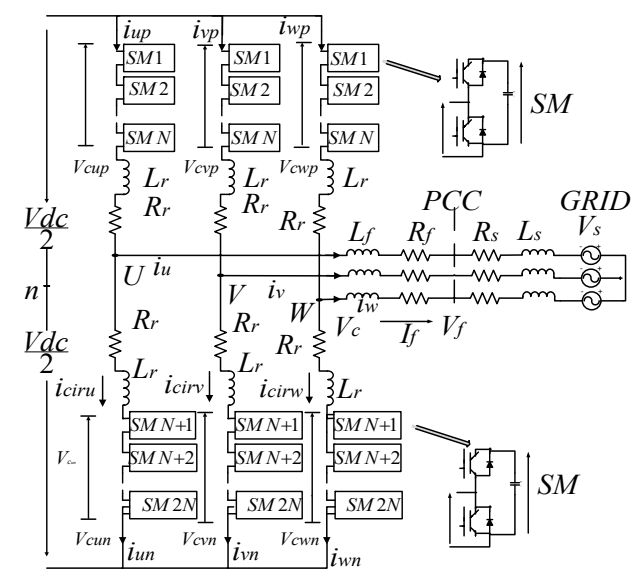

Figure 1. Grid-connected MMC based STATCOM in the three-phase configuration.

The sub-script ${ }_{k}$ represents any of the three-phases ( $u, v$ or w). Based on (1) and (2), the regulation of the circulating current $i_{\text {cirk }}$ and the output voltage $V_{c k}$ could be achieved by controlling the upper and lower currents. And the upper and lower arm voltages $\left(V_{c k p}\right.$ and $\left.V_{c k n}\right)$ given in (3) and (4) respectively.

$$
\begin{aligned}
& V_{c k p}=\frac{1}{2} V_{d c}-V_{c k} \\
& V_{c k n}=\frac{1}{2} V_{d c}+V_{c k}
\end{aligned}
$$

$V_{d k}$ is the cumulative equivalent direct current (DC) voltage across the arms. $L_{r}$ is the arm inductance of each arm. $R_{r}$ is the series resistance associated with the buffer inductance [21]. $V_{c k}$ is the MMC AC output voltage defined as:

$$
V_{c k}=\frac{1}{2} V_{d c^{*}} M \sin (\omega t)
$$


The (5) gives the output voltage under ideal conditions when each voltage of the submodules (SM) capacitor is constant and equal to the value of $V_{d k} / N, M$ and $I_{c}$ are the modulation voltage and peak output current respectively. $\omega$ and $\varphi$ are the angular frequency and load angle respectively. The basic per-phase control schemes which are averaging control, individual control, and the arm balancing control use (6)-(9) for their implementation, and the control scheme could be extended to the three-phase configuration [27]. The meaning of the symbols in Figure 2-5 are defined as

$$
\begin{aligned}
& \overline{\mathrm{V}}_{C k}=\frac{1}{2}\left(\overline{\mathrm{V}}_{C k p}+\overline{\mathrm{V}}_{C k n}\right) \\
& \overline{\mathrm{V}}_{C k p}=\frac{1}{N} \sum_{i=1}^{N} \mathrm{~V}_{C k i} \\
& \overline{\mathrm{V}}_{C k n}=\frac{1}{N} \sum_{j=N+1}^{2 N} \mathrm{~V}_{C k j} \\
& \mathrm{~V}_{C}^{*}=\frac{V_{d c}}{N}=\mathrm{V}_{C k}^{*}
\end{aligned}
$$

$\overline{V_{c k}}$ is the per-phase average capacitor voltage in the corresponding phase. $\overline{\mathrm{V}}_{C k p}$ and $\overline{\mathrm{V}}_{C k n}$ are the average capacitor voltage of the upper arm and lower arm of the corresponding phase respectively. $N$ is the number of the SM in the upper and lower arm, $\mathrm{V}_{C_{k i}}$ and $\mathrm{V}_{C_{k j}}$ are the voltages of the $i$ th and $j$ th SMs in the upper arm and lower arm respectively. $\mathrm{V}_{C k}^{*}$ and ${ }^{i_{\text {cirk }}^{*}}$ represent the reference voltage and reference circulating current in the corresponding leg respectively.

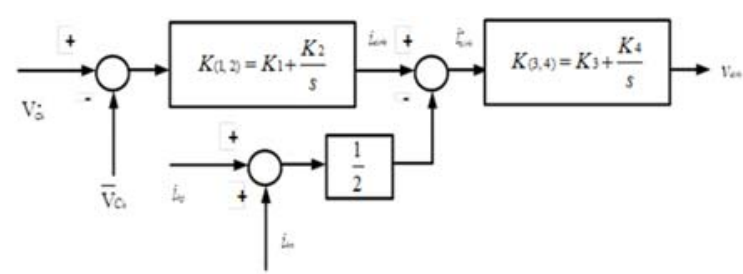

Figure 2. Block diagram of averaging control

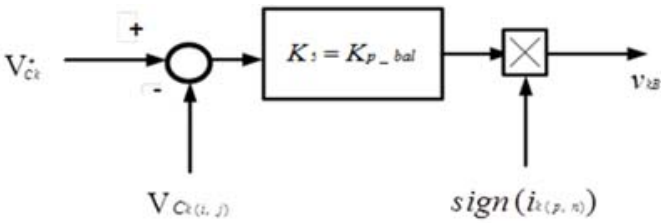

Figure 3. Individual balancing control block diagram

Figure 2 depicts the averaging loop diagram, this control pushes the average voltage $\overline{\mathrm{V}}_{C_{k}}$ of each phase leg to follow its reference voltage $V_{C k}^{*}$. When $V_{C k}^{*} \geq \bar{V}_{C k}$, $i_{c i r k}^{*}$ increases and forces the actual circulating current $i_{c i r k}$ to follow its reference current ${ }^{i_{\text {cirk }}^{*}}$ making $\overline{\mathrm{V}}_{C k}$ to track its reference voltage $\mathrm{V}_{C k}^{*}$. PI controllers can be employed in the tracking, and the output voltage command $\mathcal{V}_{\text {cirk }}$ from the averaging control can be produced for the CSPWM. The gains of the PI controllers which are $K_{1}, K_{2}, K_{3}$ and $K_{4}$ could be obtained based on internal mode control theory [28].

Figure 4. Arm balancing control block diagram
Figure 5. Voltage commands for the PWM balancing control of the MMC arm 
The individual balancing control pushes each SM capacitor voltage individually in every submodule to follow its voltage reference $\mathrm{V}_{c k}^{*}$, the individual balancing control block diagram is depicted in Figure 3. The obtained voltage command for this modulation control is $v_{k B}$. When $\mathrm{V}_{C k}^{*} \geq \mathrm{V}_{C k(i, j)}$. the arm current is charging the SM capacitor, the polarity of the output current is positive. When it is reversed, the arm current gets the opposite polarity. The proportional controller with a gain $K_{5}$ could be employed. The control block for the arm balancing is shown in Figure 4. This control lessens the discrepancies in voltages between the voltages of upper and lower arm. The voltages, $\bar{V}_{C k p}$ and $\overline{\mathrm{V}}_{C k n}$ are also known as the average voltages of the positive arm and negative arm respectively. The proportional controller $K_{6}$ could be employed. Figure 5 shows the mathematics for the overall voltage command generation for the CSPWM in the control diagram representation [29]. However, the circulating current control based on Figure 2 which is using the PI-control is usually insufficient in suppressing the circulating current [21]. Thus, voltage disturbance is introduced on the SMs and injects harmonic current during normal operation. Taking in any phase-k, the variation could be explained by the relationship between the energy stored within the MMC arms. The active energy stored in the upper and lower rams are as follows:

$$
\begin{aligned}
W_{k p} & =\frac{1}{2 N} C v_{C l p}^{2} \\
W_{k n} & =\frac{1}{2 N} C v_{C k n}^{2}
\end{aligned}
$$

Where $\mathrm{C}$ is the SM capacitance. From (10) and (11), let the active voltage disturbance which contributes to the MMC variation be written in terms of the DC component $I_{d c}$ and harmonic components $i_{n}$ as

$$
\begin{aligned}
& \Delta v_{c p}=\frac{N}{2 C} \int(1-M \sin (\omega t)) \cdot\left(\frac{i_{k}}{2}+\frac{1}{3} i_{k c}+\sum_{n=1}^{\infty} i_{n}\right) d t \\
& \Delta v_{c k n}=\frac{N}{2 C} \int(1+M \sin (\omega t)) \cdot\left(-\frac{i_{k}}{2}+\frac{1}{3} i_{d c}+\sum_{n=1}^{\infty} i_{n}\right) d t
\end{aligned}
$$

Where $\Delta v c_{k p}$ and $\Delta v c_{k p}$ are the voltage change due to disturbances in the upper and lower arms respectively. The circulating current in the MMC could be given as

$$
i_{c i r}=\frac{1}{3} i_{d c}+\sum_{n=1}^{\infty} i_{n}
$$

For typical STATCOM applications, the DC component $I_{d c}$ is zero since there is no DC link DC voltage source. The harmonic components $i_{n}$ are the nth order harmonics of the circulating current. Therefore, the real output voltages of the upper and lower arms considering the variation could be as

$$
\begin{aligned}
& V_{C k p}=\frac{1}{2}(1-M \sin (\omega t)) \cdot\left(V_{d c}+\Delta v_{C k p}\right) \\
& V_{C k n}=\frac{1}{2}(1+M \sin (\omega t)) \cdot\left(V_{d c}+\Delta v_{C k n}\right)
\end{aligned}
$$

Then considering the variation, the total output voltage of the phase leg could be given as follows: 


$$
V_{d p}+V_{d n}=V_{d c}+\frac{1}{2}\left(\Delta v_{c p}+\Delta v_{c n}\right)+\frac{1}{2} M \sin (\omega t) \cdot\left(\Delta v_{c n}-\Delta v_{c p}\right)=\left(V_{d c}+V_{k d}\right)
$$

Therefore, $v_{k d}$ is the voltage variation between the phase-leg and the total SM voltages (i.e. $V_{d c}$ ) when the system is under normal modulation. Equations (6)-(9) describe the capacitor voltage control and the active power sharing within any leg. In other words, the active power balancing is per-phase, and it is employed by adjusting the dc circulating current within the phase leg; thus, it has no influence on the total active power absorbed by the STATCOM at the grid three-phase interface [1]. To control the active power and the reactive power at the grid PCC shown in Figure 1, the grid-interface references for the instantaneous active current ${ }^{*}{ }_{f d}^{*}$ and the reactive current ${ }_{f f q}^{*}$ could be obtained as follows:

$$
I_{f d}^{*}=K\left(\overline{\mathrm{V}}_{C}-\mathrm{V}_{C}^{*}\right)
$$

$K$ is the proportional controller gain. $\mathrm{V}_{c}^{*}$ is the reference DC voltage for the SM capacitors. $\overline{\mathrm{V}}_{C}$ is the arithmetical average capacitors voltage of all the SM capacitors in the three legs and defined as

$$
\overline{\mathrm{V}}_{C}=\frac{1}{3} \sum_{k=u, v, w} \overline{\mathrm{V}}_{C k}
$$

The reactive current reference $I_{f q}^{*}$ could be as in [14], assuming all the load reactive power is obtainable from the STATCOM. This could be defined as

$$
I_{f q}^{*}=\frac{Q^{*}{ }_{L}}{V_{f d}}=I_{L q}
$$

where $Q_{L}$ and $I_{L q}$ are the reactive load power and current respectively. $V_{f d}$ is the MMC output voltage in the d-axis usually aligned with the grid voltage using the phase-locked loop. Neglecting the grid source impedance ( $L_{s}$ and $R_{s}$ ) in Figure 1, the relationship between the grid AC voltage $\left({ }^{V_{f}}\right)$, and MMC based STATCOM AC output voltage $\left(V_{c}\right)$ in the d, q forms:

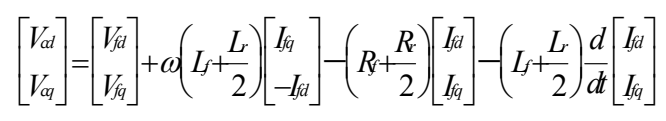

In (21), ${ }^{I_{f q}}$ represents the reactive current of the MMC in q-axis, while ${ }^{I_{f d}}$ is the active current in the d-axis. $V_{c d}$ and $V_{c q}$ are the d-axis and q-axis MMC output voltage respectively. $V_{f q}$ is q-axis grid voltage. The MMC-to-grid impedance is as

$$
Z_{T}=L_{f}+\frac{L_{r}}{2}+R_{f}+\frac{R_{r}}{2}=L_{T}+R_{T}
$$

Using the $Q_{d, q}$ variable in (23) and (24), and assuming the STATCOM currents track their current references as in [14], the MMC output voltage could be controlled using (25).

$$
\begin{aligned}
& Q_{d}=V_{f d}-V_{c d}+\omega L_{I I} I_{f q}-R_{I I} I_{f d} \\
& Q_{q}=V_{f q}-V_{c q}-\omega L_{I I f d}-R_{I I} I_{f q}
\end{aligned}
$$




$$
\begin{aligned}
& Q_{i, q}=K_{P_{-} i(d, q)}\left(I_{f}^{*}(d, q)-I_{f(d, q)}\right)+K_{I_{-} i(d, q)} \int\left(I_{f^{*}(d, q)}^{*}-I_{f(d, q)}\right) d t \\
& V_{c d}^{*}=-Q_{i}+V_{f d}+\frac{\omega L_{T}}{2}\left(I_{f q}+I_{f q}^{*}\right)-R_{I I f d} \\
& V_{c q}^{*}=-Q_{q}+V_{f q}-\frac{\omega L_{T}}{2}\left(I_{f d}^{*}+I_{f d}\right)-R_{I I f}
\end{aligned}
$$

\section{THE PROPOSED VIRTUAL IMPEDANCE AND VECTOR CONTROL COMPENSATIONS}

The proposed control introduces extra voltage compensation in the external control of the MMC with the grid and adds an extra compensation support in the internal control. These two compensations are employed to form the overall control. Unlike [14] and [30], in this control, voltage compensation is considered instead of current which has to pass through the PI-controllers or P-controllers and adds additional stress on the controllers during the transients. Also unlike [14], the negligible active current transfer is considered to enhance the d-axis control, and extra compensation in the internal control is introduced to enhance the capacitors voltage balancing. This would, in turn, enhance the active power balancing within the STATCOM; thus, enhancing the overall system control. Principles of transient impacts employed in [31] and the capacitors voltage variation are summed up to generate an extra transient voltage support to the PI controllers at the grid interface during the transients.

\subsection{External control voltage compensation of the MMC}

In Figure 1, the d-q voltage drop which contribute to the small variations between the STATCOM desired voltage commands ( $V_{c d}^{*}$ and $V_{c q}^{*}$ ), and the STATCOM voltages ( $V_{c d}$ and $V_{c q}$ ), are given in the daxis and q-axis forms as

$$
\begin{gathered}
V^{*}{ }_{c d}-V_{c d}=\Delta V_{c d} \\
V_{c q}^{*}-V_{c q}=\Delta V_{c q}
\end{gathered}
$$

Since fast speed response with minimal variation is the aim of STATCOMs, these voltage deviations ( $\Delta V_{c d}$ and $\Delta V_{c q}$ ) could be subtracted in form of compensation to mitigate the variations, and speed up the current response during the transients. The voltage compensation is derived as from (26) and (27), the corresponding desired STATCOM currents would have small deviations from their corresponding output currents, these variation are defined as

$$
\begin{gathered}
I_{f q}^{*}-I_{f q}=\Delta I_{f q} \\
I^{*}{ }_{f d}-I_{f d}=\Delta I_{f d}
\end{gathered}
$$

Assume the resistance in (22) to be zero, and the total interfacing inductance $L_{T}$ in (22) which also contributes to the STATCOM variations is modified due to high-switching [31] and considered as

$$
L_{T c o m} \geq L_{f+} \frac{L_{r}}{2}
$$

To reduce the variation assuming it happens during the transient time (i.e. $\Delta t$ ), in order to speed up the response of the PI-controller and reduce the current error in (28) and (29), an additional transient voltage could be derived from (21) as

$$
\Delta V_{q}=-L_{T c o m} \cdot \frac{\left(I_{f q}^{*}-I_{f q}\right)}{\Delta t}-\omega L_{T c o m} I_{f d}
$$

Since the variation happens during the transient time (i.e. $\Delta t$ ) in every switching period [31], the switching frequency (i.e. $f_{s}$ ) could be estimated as the inverse of the transient time for the introduced compensation, and the compensating voltage in the q-axis would then be as

$$
\Delta V_{q}=-f_{s} \cdot L_{T c o m} \cdot \Delta I_{f q}-\omega L_{T c o m} I_{f d}
$$

\footnotetext{
Modular multilevel converter (MMC) based STATCOM with vector control... (Abdurrahman Umar Lawan)
} 


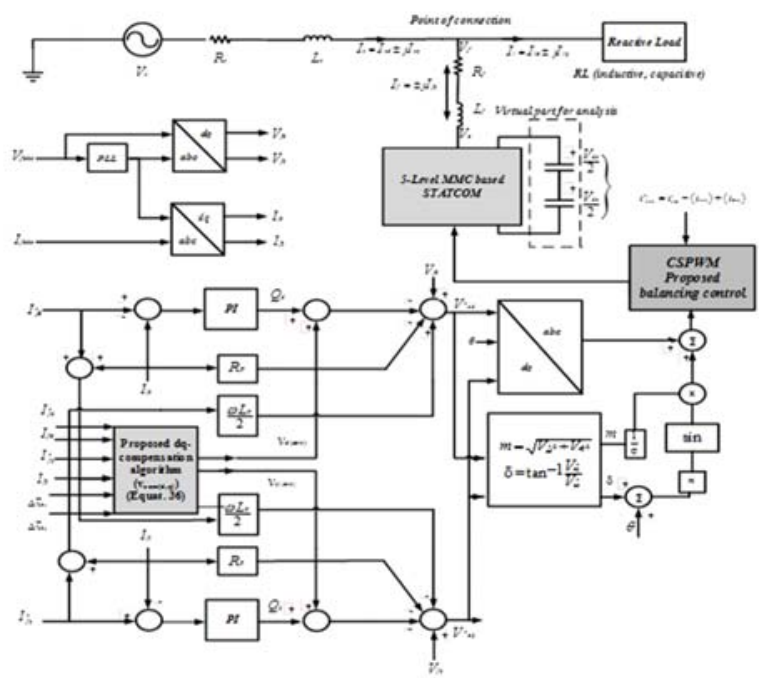

Figure 6. MMC based STATCOM system with the proposed external and internal control schemes.

Similarly, from (21), the corresponding active voltage compensation would be derived as:

$$
\Delta V_{d}=-L_{\text {Tcom }} \frac{d\left(\Delta I_{f d}\right)}{d t}-R_{\text {Tcom }} I_{f d}+\omega L_{\text {Tcom }} I_{f q}
$$

Similarly (33) is simplified further as:

$$
\Delta V_{d}=-f_{s} \cdot L_{T c o m} \cdot\left(\Delta I_{f d}\right)-R_{T c o m} I_{f d}+\omega L_{T c o m} I_{f q}
$$

During the transients, the voltage drop variables (i.e. $R_{T c o m} I_{f d}, \omega L_{T c o m} I_{f d}, R_{T c o m} I_{f q}$, and $\omega L_{T c o m} I_{f q}$ in (34) and (32) can be considered as non-transient terms, whose variations can be adequately controlled by the PI controllers; thus, ignored. In the other hand, (17) shows how the voltage variation $V_{k d}$ could contribute to the emergence of a small active power difference between the three-phase active power at the grid, and the summation of the three average per-phase active power controlled within the MMC using Figure 2-5.

In other words, the contribution of the internal active voltage disturbance produced in each leg/phase explained in Section II [21] is considered.

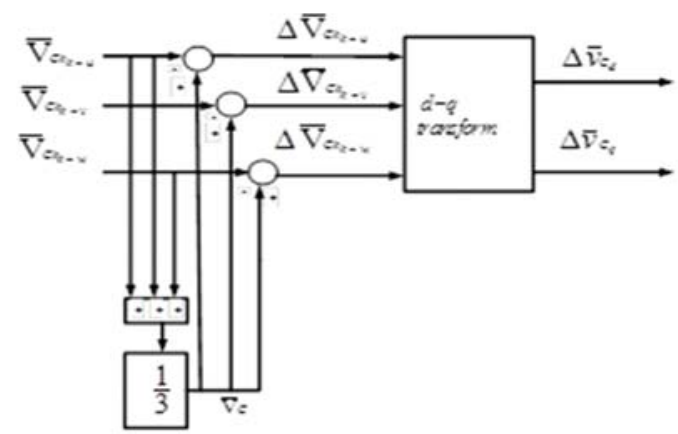

Figure 7. Voltage variation d-q components

Thus, these variations produce the capacitor voltage d-q variation components shown in Figure 7. In other words, the arithmetical average dc capacitor voltage of all the phases, i.e. $\overline{\mathrm{V}}_{C}$, and the arithmetical mean dc capacitor voltage of each phase will produce voltage variation d-q components as shown in Figure 7. 


$$
\text { Using the d-q transform, it is possible from the voltage differences } \Delta \overline{\mathrm{V}}_{C k_{k=u}}, \Delta \overline{\mathrm{V}}_{c_{k=v}} \text { and } \Delta \overline{\mathrm{V}}_{C k_{k=w}} \text { to }
$$
obtain the d-q variation components $\Delta \bar{v}_{C d}$ and $\Delta \bar{v}_{C q}$. The angle $\phi$ represents the extent of the voltage variation among the SM capacitors with respect to the STATCOM output currents in the d-q frame, and is given as

$$
\phi=\tan ^{-1} \frac{I_{f q}}{I_{f d}}-\tan ^{-1} \frac{\Delta \bar{v}_{C q}}{\Delta \bar{v}_{C d}}
$$

Then the corresponding total voltage variation in the d-q frame given in (32) and (34), could be modified with respect to the voltage variation among the SM capacitors, and given as

$$
\left.\begin{array}{l}
v_{\text {doom }}=-f_{s} \cdot L_{\text {Tom }} \cdot\left(\Delta_{f d}\right)-\left(\Delta \bar{v}_{c d}\right) \\
v_{q c o m}=-f_{s} \cdot L_{\text {Tom }} \cdot\left(\Delta_{f q}\right)-\left(\Delta \bar{v}_{c q}\right)
\end{array}\right\}
$$

The opposing signals $\mathcal{V}_{\text {dcom }}$ and $v_{q c o m}$ in (36) are to be considered as the compensating signals to the PI control actions in the d-q control. The compensating variables $v_{\text {dcom }}$ and ${ }^{v_{\text {qcom }}}$ are then added to the outputs of the d, q-PI controllers ( $Q_{d}$ and $Q_{q}$ ) in the voltage reference equation given in (25). This will generate the enhanced compensated voltage reference $\left(V^{*}{ }^{2}(k)\right.$ and $V^{*}{ }_{c q}(k)$ ) given in (37). From (36), once the steadystate is reached, the capacitors voltage variations $\Delta \bar{v}_{C d}$ and $\Delta \bar{v}_{C q}$ in Figure 7 and the current variations $\Delta I_{f d}$ and $\Delta I_{f q}$ cease to prevail. This will make the compensation to cease to exist.

$$
\left.\begin{array}{c}
V_{c d}^{*}=-Q_{d}+v_{d c o m}+V_{f d}+\frac{\omega L_{T}}{2}\left(I_{f q}+I_{f q}^{*}\right)-R_{I I} I_{f d} \\
V_{c q}^{*}=-Q_{q}+v_{q c o m}+V_{f q}-\frac{\omega L_{T}}{2}\left(I_{f d}^{*}+I_{f d}\right)-R_{T I} I_{f q}
\end{array}\right\}
$$

\subsection{MMC internal control using virtual impedance based compensation}

The voltage variation from within the MMC discussed in Section II, is a voltage ripple and produces the DC circulating current $i_{\text {cirk }}$ with ripple current components [32]. The use of the PI-controllers in the internal control of the MMC is one of the most common solutions to obtain a zero static error in controlling the dc circulating current. However, PI-controllers have the small effect in suppressing the harmonic voltage unless a high-gain high-order controllers such as resonant controllers are employed with the PI-controllers. Based on the integral feature of resonant controllers, the suppression of the low-order harmonic voltage could be achieved. This control is mostly achieved using second-order resonant controllers for the low harmonics. To cancel high-order harmonics, large-order resonate controllers have to be employed.

And many of them have to be cascaded for better harmonics elimination [21]. Note, the bandwidth of the circulating current controllers are very small due to the limited sample and processing frequency in MMCs; thus, increasing the order of the resonant controller could not be feasible [21]. Another approach to reducing the impacts of the voltage harmonics is the use of the repetitive controller. However, the repetitive controller design requires a complex stability analysis on the controller-filter design. Moreover, the implementation of repetitive controller requires a heavy digital signal processing. From Section II, the active voltage disturbance ${ }^{v_{k d}}$ contributes to the STATCOM distortion in each phase leg, by generating voltage variation between the leg and the total $\mathrm{SM}$ voltages (i.e. $V_{d c}$ ). If the variation could be minimized, by injection of an external virtual current opposing the circulation current, the voltage disturbance impacts could be mitigated; thus, the total output voltage would equate the total SMs voltages. And the voltage distortions would become minimal.

This section considers the improved model of circulation current developed in [21], which considers the presence of the voltage disturbance in the closed loop. Also, it employs the virtual impedance concept based on droop-method to increase the MMC internal impedance and lessen the amount of the unwanted circulation current [12]. To check the influence of the virtual impedance in ensuring an improved steady-state and dynamic performance, the PI-controller in Figure 8 will have $k_{p}$ as the proportional coefficient, $k_{i}$ as the

\footnotetext{
Modular multilevel converter (MMC) based STATCOM with vector control... (Abdurrahman Umar Lawan)
} 
integral coefficient, and have the open-loop transfer function as $G_{i}(s)$. Therefore, the dynamic behavior of the closed-loop would be as follows:

$$
i_{c i r c}(s)=\frac{\left(k_{p_{-} i} S+k_{i_{-} i}\right) i_{i r i k}^{*}(s)}{L_{r} S+R_{r}+k_{p_{-} i}+k_{i_{-} i}}-\frac{V_{k d}(s)}{2\left(L_{r} S+R_{r}+k_{p_{-} i} i k_{i_{-}} i\right)}(38)
$$

From (38), it could be seen that the internal circuit could be modeled in the equivalent form as

$$
i_{\text {circ }}(s)=g(s) . i_{\text {cirk }}^{*}(s)-\frac{V_{k d}(s)}{Z_{o}(s)}
$$

$g(s)$ is the circulating current reference-to-measured circulating current transfer function, and $Z o(s)$ is the impedance transfer function of the closed-loop system.

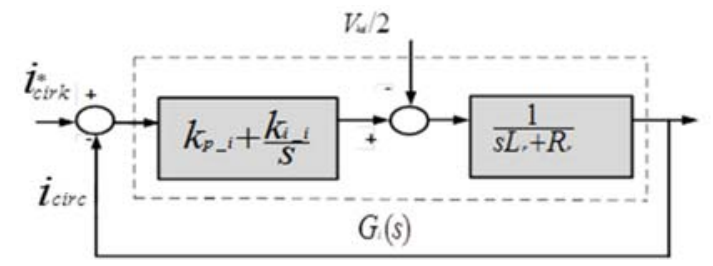

Figure 8. Improved circulating current control using conventional PI controller

Considering (39), it is clear that the impedance $Z_{o}(s)$ affects the circulating current control. To impose a desired impedance $Z_{v}(s)$ and reduce the impact of the voltage disturbance for an improved stability, the current reference $i_{\text {cirk }}^{*}(s)$ could be obtained from a new desired current reference $i_{\text {cirk }}^{i_{*}^{*}}(s)$ as a function of the voltage disturbance. This could be achieved by the droop-method as

$$
i_{c i r k}^{*}(s)=i_{c i r k}^{k_{k}}(s)-\frac{V_{k d}(s)}{Z_{v}(s)}
$$

where $Z_{v}(s)$ is the virtual impedance, and could be obtained by taking the time derivative of a virtual inductance $L_{v i r}$ (i.e. $Z_{v}(s)=s L_{v i r}$ where s is the Laplace operator).

Putting (40) into (39), the dynamic equation of the internal current-loop of the MMC could be modified as follows :

$$
\begin{aligned}
& i_{\text {circ }}(s)=g(s) . i_{\text {cirk }}^{k_{k}}(s)-V_{k d}(s) \frac{g(s)\left(Z_{o}(s)+Z_{v}(s)\right)}{Z_{v}(s) Z_{o}(s)} \\
& Z_{o v}(s)=\frac{Z_{v}(s) Z_{o}(s)}{g(s)\left(Z_{o}(s)+Z_{v}(s)\right.} \text { is the average capacis }
\end{aligned}
$$

function. The stability effects of this virtual impedance in the closed loop system are described in Section IIIC. It has been reported that the use of the derivative of virtual impedance $Z v(s)=s L_{v i r}$ increases the total internal impedance, and reduces the circulation of unwanted current [33]. However, with the presence of noise, especially in the experimental operations of the MMC, the derivative term amplifies the noise in the system [12]. To minimize the amplified noise usually generated by the derivative virtual impedance, a low pass filter (LPF) could be employed along with the derivative based impedance. However, it has been reported that the LPF can introduce an additional delay which depends on the types of the operating parameters such as the loads and filters in the system [21]. In the other hand, the virtual transient impedance concept could be employed to generate opposing virtual current signals (i.e. ${ }^{i_{\text {cvir }}}$ and $i_{\text {Lvir }}$ ) with the stability enhancement without the increase in the system delay. From (41), it could be seen that the enhanced total

Int J Pow Elec \& Dri Syst Vol. 10, No. 4, Dec 2019: 1833 - 1851 
impedance $^{Z} Z_{o v}(s)$ could be obtained by paralleling the virtual impedance $Z v(s)$ with the original impedance $Z_{o}(s)$ to improve the system stability. Therefore, the voltage disturbance $V_{k d}$ which could be obtained from (17), augmented with the measured average voltage $\bar{V}_{C k}$ from the original system will produce a variable $v$ for an improved stability as shown in Figure 9. Taking the time-integral of the voltage $v_{\text {to }}$ avoid the use of the time-derivative for possible noise amplification, gives the virtual inductor current ${ }_{L_{\text {Lvir }}}$ as

$$
i_{L v i r}=\frac{1}{L_{v i r}} \int v d t
$$

To avoid the disadvantage of the introduction of virtual impedance in the system, which is imposing voltage drop during steady state [12], $v_{\text {is made to be the function of voltage variation }} V_{k d}$; thus, the current $i_{\text {Lvir }}$ reduces as soon as the voltage variation is no more at the steady state. This virtual inductor ripple current is to be an opposing signal to the ripple current in the circulating current. Thus, decreasing the effective ripples in the system. To impose the injection of only the ripple current in the loop for stability enhancement and ripple reduction, another virtual term (i.e. ${ }_{i \text { cir }}$ virtual capacitor) will be introduced to generate a virtual capacitor current $i_{\text {cvir }}$ which produces an active current component. This would be opposing the active current component in the produced virtual inductor current $i_{L v i r}$. This is possible as both currents $\left(i_{c \text { cir }}\right.$ and $\left.i_{\text {Lvir }}\right)$ are the function of the measured average capacitor voltage. Since the measured capacitor voltages are obtained mostly using LPF or moving average filters (MAF) [34-37] the virtual capacitor current $i_{\text {cvir }}$ could be generated from the measured voltage variation shown in Figure 9, with minimal noise without the use of any additional filter, and given by:

$$
\begin{aligned}
& i_{\text {cvir }}=K_{v i r}\left(\mathrm{~V}_{C k}^{*}-\overline{\mathrm{V}}_{C k}\right) \\
& K_{\text {virc }} \text { is the virtual capacitance term that could be given as: } \\
& K_{\text {virc }}=\frac{C_{\text {virc }}}{T_{\text {virc }}}
\end{aligned}
$$

The time constant should be made higher than the switching period (i.e. $T_{\text {vir }} \gg T_{s}$ ), this would make the virtual capacitor current nearly constant throughout the discharge and charge period.

The new reference current could be obtained by the addition of the virtual currents to the original reference current as

$$
i_{\text {cirk }}^{\prime *}=i_{c i r k}^{*}-\left(i_{c v i r}\right)+\left(i_{\text {Lvir }}\right)
$$

where $i_{\text {cirk }}^{\prime \prime}$ is the drooped circulating current reference. Therefore, the outer-loop average capacitor voltage is droop-controlled as follows:

$$
i_{c i r k}^{\prime *}=K_{1}\left(\mathrm{~V}_{C k}^{*}-\overline{\mathrm{V}}_{C k}\right)+K_{2} \int\left(\mathrm{V}_{C k}^{*}-\overline{\mathrm{V}}_{C k}\right) d t
$$

The virtual impedance control enhancement provides an improved stability without the use of any additional sensing knowledge, filtering or sensing devices. Once the system is in the steady state, the two virtual currents stop. Figure 9 shows the closed-loop diagram of the proposed virtual impedance-based average capacitor voltage control. The other integral controls within the leg-k which are the arm balancing control and the individual balancing control are maintained, and given by (47) and (48) respectively. 


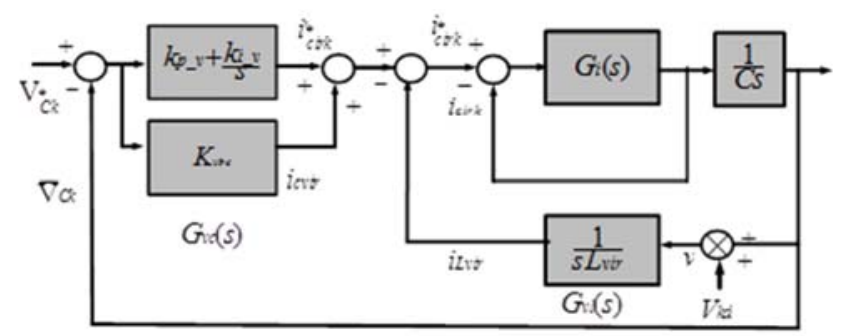

Figure 9. The closed-loop diagram of the proposed virtual impedance-based average capacitor voltage control

$$
\begin{aligned}
& v_{k A}=K_{5}\left(\overline{\mathrm{V}}_{C k p}-\overline{\mathrm{V}}_{C k n}\right) i_{k} \\
& v_{k B}= \pm K_{6}\left(\mathrm{~V}_{C k}^{*}-\mathrm{V}_{C k(i, j)}\right)
\end{aligned}
$$

Adding all the balancing control commands (i.e. ${ }^{v_{\text {cirk }}, v_{k A}}$ and ${ }^{v_{k B}}$ ) to the MMC phase AC output voltage $V_{c k}$ and the DC-link voltage $\left(v_{k c}=V_{d c} / 2 N\right)$ will give the CSPWM voltage command $v_{k i j}^{*}$ for the upper and lower arms as

$$
\begin{aligned}
& v_{k i}^{*}=v_{c i r k}+v_{k A}+v_{k B}+v_{k C}-\frac{V_{c k}}{N} \\
& v_{k j}^{*}=v_{c i r k}+v_{k B}+v_{k C}+v_{k D}+\frac{V_{c k}}{N}
\end{aligned}
$$

\subsection{Stability analysis of the virtual impedance incorporation}

This analysis will be carried out using the improved model of the inner current control. Thus, the voltage disturbance $V_{k d}$ is considered to be present in the inner-current control. This is a transfer function based analysis; thus, for simplicity, the variable $V_{k d}$ is assumed constant and given a unity value in the outerloop. Based on these two assumptions, a reduced closed-loop diagram depicted in Figure 10 is formed.

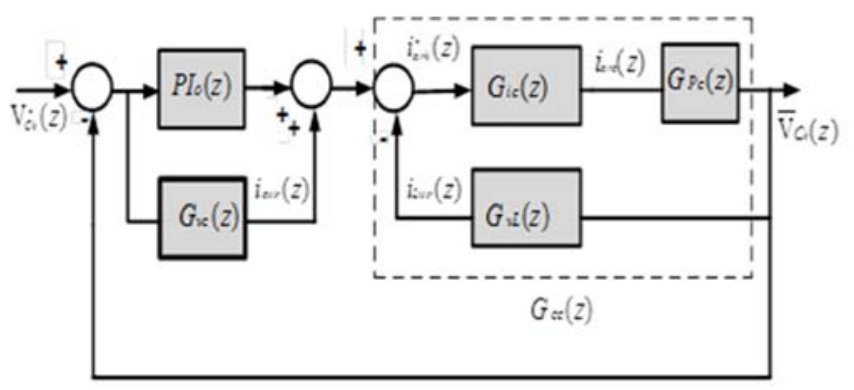

Figure 10. The reduced closed-loop diagram of the virtual impedance-based average capacitor voltage control

The purpose of this analysis is to analyze the stability criteria of the virtual impedance placement based on their transfer functions (i.e. $G_{v c}(z)$ and $G_{v L}$ ). $G_{p}(z)$ is the plant model for the inner current written as:

$$
G_{P}(z)=\frac{T_{s}}{(z-1) L_{r}}
$$


Where $T_{s}$ is the sampling period. $G_{p c}(z)$ is the assumed average capacitor model as in [35-40]. The proportional integral controllers in the z-domain for the inner circuiting current control (i.e. $P I_{I}(z)$ ) and the outer capacitors voltage control (i.e. $P I_{o}(z)$ ), could be written in the z-domain as (52) and (53) respectively.

$$
\begin{aligned}
& P I_{I}(z)=\frac{\left(k_{p_{-} i}+k_{i_{-}} i T_{s}\right) z-k_{p i}}{z-1} \\
& P I_{o}(z)=\frac{\left(k_{p_{-} v}+k_{v_{-}} \cdot T_{s}\right) z-k_{p v}}{z-1}
\end{aligned}
$$

$G_{i c}(z)$ is the closed-loop transfer function of the inner control depicted in Figure 10. The relationship between the reference circulating current ${ }_{i \text { cirk }}^{*}(z)$ and the inner circulatingcurrent ${ }_{i \text { circ }}(z)$ could be written as:

$$
i_{\text {circ }}(z)=\frac{P I_{I}(z) D(z) G_{P}(z)}{1+P I_{I}(z) D(z) G_{P}(z)} \cdot i_{\text {cirk }}^{*}(z)-\frac{G_{P}(z)}{1+P I_{I}(z) D(z) G_{P}(z)} \cdot \frac{V_{k d}(z)}{2}
$$

$D(z)$ represents the inner-current control delay. The error $e(z)$ which is introduced in terms of the voltage disturbance and the new circulating current reference ${ }^{i_{\text {cirk }}^{\text {"k }}(z)}$ could be given as in (55).

$$
\left.\begin{array}{c}
e(z)=\frac{i_{c i r k}^{*}(z)+G_{P}(z) \cdot V_{k d}(z) / 2}{1+P I_{I}(z) D(z) G_{P}(z)} \\
i_{\text {cirk }}^{\nu_{k}}(z)=\left(i_{\text {cirk }}^{*}(z)-i_{c v i r}(z)\right)+i_{L v i r}(z)
\end{array}\right\}
$$

If the inner circulating current control system is stable, the closed-loop eigenvalues of $e(z)$ given by (55) have to be in the z-domain within the unit cycle. For the outer-loop averaging capacitor voltage control, the relationship between the capacitor average voltage $\overline{\mathrm{V}}_{C_{k}}(z)$, and its reference $\mathrm{V}_{c k}^{*}(z)$ could be defined as:

$$
\overline{\mathrm{V}}_{C_{k}}(z)=\frac{\left(P I_{o}(z)+G_{v c}(z)\right) G_{c c}(z)}{1+\left(P I_{o}(z)+G_{v c}(z)\right) G_{c c}(z)} \cdot \mathrm{V}_{c k}^{*}(z)
$$

$G_{v c}(z)$ is the virtual capacitance controller, and given by:

$$
G_{v c}(z)=\frac{C_{v i r}}{T_{v i r}}
$$

$T_{v i r}$ is the time constant and for stability, it has to be selected larger than the sampling period $T_{s}$ so as to remain at a constant value throughout the transient period. From Figure 10, for simplicity, a transfer function $G c c(z)$ is derived to form an outer-loop given by:

$$
G_{c c}(z)=\frac{G_{i c}(z) \cdot G_{p c}(z)}{1+G_{v L}(z) G_{i c}(z) \cdot G_{p c}(z)}
$$

$G_{p c}(z)$ is the voltage plant model and is given by:

$$
G_{p c}(z)=\frac{T_{s}}{z-1} \cdot \frac{1}{C}
$$



and given by:

$G_{v L}$ is the feedback term of the semi-outer loop $G_{c c}(z)$ defined as the virtual inductance controller

$$
G_{v L}=\frac{T_{s}}{(z-1) L_{v i r}}
$$

For stability, the bandwidth of the semi-loop $G_{c c}(z)$ with a feedback ${ }^{v L}$ should be higher than the bandwidth of the current control. For analysis to be simplified, $F(z)$ is as

$$
F(z)=P I_{o}(z) G_{c c}(z)
$$

The characteristics polynomial of the overall loop could be as

$$
H(z)=(1+F(z)) \cdot\left(1+\frac{G_{v c}(z) G_{c c}(z)}{1+F(z)}\right)
$$

Using Figure 9, (62) could be further simplified as follows:

$$
\begin{aligned}
& H(z)=(1+F(z)) \cdot\left(1+\frac{P(z)}{1+F(z)}\right) \\
& P(z) \text { is given as in }(64) . \\
& P(z)=\frac{G_{i c}(z) \cdot G_{p c}(z) G_{v c}(z)}{1+G_{v L}(z) G_{i c}(z) G_{p c}(z)}
\end{aligned}
$$

From (62) and (63), the following two stability conditions should be achieved for the system to be stable:

a) The zeros of the polynomial $(1+F(z))$ have to be within a unit cycle of the $z$-domain, in the other words, the semi outer loop $G_{c c}(z)$ with a feedback term $G_{v L}(z)$ has to be stable before the virtual term $G_{v c}(z)$ is paralleled.

b) Zeros of the polynomial $P(z)$ given in (63) should also be in the z-domain within the unit cycle. In other words, the zeros of the $P(z)$ have to be on the right-hand side on the root locus plane.

\section{DIGITAL IMPLEMENTATION AND RESULTS}

The proposed control implementation is done in a digital form, hence presented in $\mathrm{z}$-domain, the stability analysis is carried out in a discrete domain. The purpose of the proposed control is to enhance the averaging voltage control with fewer voltage ripples. The capacitors voltage ripple is the source of the circulating current [32]. Therefore, the reduced ripple would result in providing more suppressed circulating current. The measured variables described in (1)-(9), and the voltage difference in (17) are fed into the Simulink model. This approach is for both simulation and experimental studies. The STATCOM step change is obtained by the load transition from capacitive to inductive mode.

The discrete outer voltage PI-controller (i.e. $P I_{o}(z)$ ) of the average capacitors voltage is paralleled with the virtual capacitance controller. In other words, the current $i_{\text {cvir }}(z)$ is obtained from the output of the voltage control PI-controller and then added to the new virtual capacitor current $i_{\text {cvir }}(z)$ which is the output of the virtual controller $G_{v c}(z)$. The new voltage controller output current i.e. $\left(i_{c i r}(z)-i_{c v i t r}(z)\right.$, when added to the virtual inductance current $\left(i_{\text {Lvir }}(z)\right.$, produces a new reference circulating current $i_{\text {cirk }}^{l_{*}}(z)$. The discrete error signal $(e(z)$ ) described in (55), which is the difference signal between the sampled signal (i.e.

Int J Pow Elec \& Dri Syst Vol. 10, No. 4, Dec 2019: 1833 - 1851 
$i_{\text {circ }}(z)$ ) and the set-point signal (i.e. ${ }^{i_{\text {cirk }}^{*}(z)}$ ), is corrected by the discrete PI controller based on the Euler algorithm [36].

\subsection{Simulation result}

The simulation has been done using the Table 1 and Table 2 parameters. The time domain step responses based on the proposed scheme are presented in Figure 11 to Figure 20. Figure 11 has shown that the zeros and poles of the polynomial and derived in (62) and (63) are on the left-hand side of the root locus plane. This means is stable before the virtual capacitance control term is paralleled in the system. In other words, the system ability to become unstable in the proposed closed-loop process is increased as the phase margin has increased from 93.9 degrees in the conventional averaging to a value of 102 degrees in the proposed averaging. Figure 12 shows the root locus of the proposed and conventional closed-loop averaging voltage controls. It could be seen that the zero of the original voltage control concept (conventional) that is close to the origin is at a point X:-32.02, Y: 0 . This zero at the point X:-32.02, Y: 0 has been replaced (i.e. by position in the root locus diagram) in the proposed scheme with a zero at a point X:-477, Y: 0. Similarly, the zero in the conventional scheme at a position X:-5561, Y: 0 which is far away from the zero axes, has been replaced by another zero at position X:-5584, Y: 0 . However, both schemes have conjugate pairs of zeros but their importance has been outweighed by the zeros positions on the real axis line for their contribution to stability. In other words, their closeness to the zero origin in the root locus plot. The (55) has been employed to study the voltage disturbance suppression capability for the proposed and conventional control schemes. The gain performances to disturbance rejection have been shown in Figure 13, and can be seen that the proposed closed-loop averaging control has a greater suppression ability throughout the high-frequency range $(100 \mathrm{~Hz}$ to $1 \mathrm{MHz})$ than that of the conventional averaging. Figure 14 shows the steady-state per-phase AC voltage of the MMC and the grid using the proposed scheme. Figure 15 (a) shows the MMC output active current control response in the d-axis form in full response. That is, from the introduction of the load (i.e. during the start-up) to the transition state. Figure 15 (b) shows the expanded-view response during the transition (i.e. step change in the reactive load). For STATCOM application, the active current supposed to be small. The active current has been negligible as shown in Figure 15 (b). Figure 15 (c) shows the reactive current control response in full form. Figure 15 (d) shows the reactive current control response during the reactive load transition. The active current response exhibits less overshoot compared to the reactive current response. This is due to the action of the transient virtual impedance carried out in the capacitors voltage current.

Figure 16 and Figure 17 show the per-phase MMC output voltage produced by the proposed control and conventional control respectively, during the start-up, the conventional MMC output voltage has a delay of 0.2 seconds before it reaches its steady-state value of 50-vac. In other words, there is increase in the settling time of about 0.1 seconds during the start-up between the inner current controls in Figure 15 and their corresponding outer-loop output voltage responses due to the process delay. This delay is shown in form of the voltage distortion and has been found to be mitigated by the virtual impedance voltage support as shown in Figure 16. This virtual impedance-based balancing control has improved the voltage levels of the MMC irrespective of the reactive load. Figure 18 shows the combined responses of the circulating currents, it can be seen that the circulating current using the conventional approach has a similar response as in Figure 17 (i.e. the delay of 0.2 seconds with oscillations).

Figure 19 shows the capacitor voltages using the conventional and proposed methods. The balancing using the proposed has shown an enhancement, in other words, the balanced capacitor voltages using the conventional techniques have more distortions, and these distortions could be seen during the startup and slightly during the steady-state process. Note: LFPs are used for the measured capacitors voltages; thus, the results shown in Figure 19 would have been better with reduced AC contents if MAFs were employed. The voltage error signal, which is the difference signal between the sampled average voltage signal (i.e. $\overline{\mathrm{V}}_{C k}(z)$ ) and the set-point voltage signal (i.e. $\mathrm{V}_{C k}^{*}(z)$ ) is corrected by the discrete voltage PI controller. The results are then presented.

Table 1. Control Parameters of the capacitor voltage balancing for the stimulation and experiment

\begin{tabular}{clc}
\hline Symbol & \multicolumn{1}{c}{ Quantity } & Value \\
\hline$K 1$ & Proportional inner DC current gain & 0.16 \\
$K 2$ & Integral inner DC current gain & 49 \\
$K 3$ & Proportional outer DC capacitor voltage gain & 7.5 \\
$K 4$ & Integral outer DC capacitor voltage gain & 375 \\
$K 5$ & Proportional arm DC voltage gain & 0.5 \\
$K 6$ & Proportional individual cap. DC voltage gain & 0.5 \\
\hline
\end{tabular}

Modular multilevel converter (MMC) based STATCOM with vector control... (Abdurrahman Umar Lawan) 
Table 2. Parameters of the grid-connected MMC for simulation and experiment

\begin{tabular}{clc}
\hline Symbol & \multicolumn{1}{c}{ Quantity } & Value \\
\hline$f$ & Fundamental frequency & $50 \mathrm{~Hz}$ \\
$f_{s w}$ & Switching frequency & $4 \mathrm{kHz}$ \\
$V_{f}$ & Grid voltage & $50 \mathrm{Vac}$ \\
$R_{s}$ & Grid resistor & $0.500 \mathrm{~m} \Omega$ \\
$L_{s}$ & Grid inductor & $0.120 \mathrm{mH}$ \\
$R_{f}$ & AC coupling resistor & $0.100 \mathrm{~m} \Omega$ \\
$L_{f}$ & AC coupling inductor & $2 \mathrm{mH}$ \\
$R_{r}$ & MMC buffer resistor & $0.400 \mathrm{~m} \Omega$ \\
$L_{r}$ & MMC buffer inductor & $2 \mathrm{mH}$ \\
$C_{e}$ & Effective capacitor(s) & $800 \mathrm{uF}$ \\
$V_{D C}$ & SM reference DC voltage & $50 \mathrm{~V}$ \\
$R L$ & Active/inductive Load (kw/Kvar) & $500 / 500$ \\
$R C$ & Active/capacitive Load (kw/Kvar) & $500 / 500$ \\
$K_{P \_} d, q$ & d-q-axis proportional current gain & 2800 \\
$K_{I-q} d q$ & d-q-axis Integral inner current gain & 300 \\
\hline
\end{tabular}

Currents drawn by the load from the grid Oscillations are clearly seen in the response using the conventional method. It is seen that the currents drawn by the load using the proposed method have fewer distortions. Figs. 15-20 have shown that the external compensation has improved the d-q current response and the virtual impedance has improved the capacitor voltage control, which, in turn, improved the MMC output voltage levels especially during the start-up.

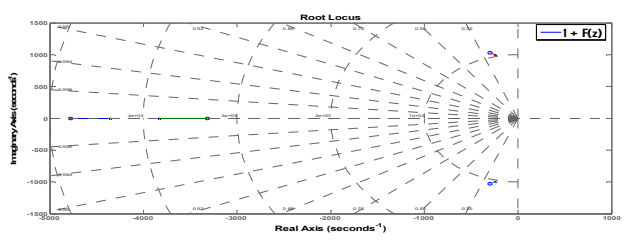

Figure 11. Root locus of the zeros of the polynomial $(1+\mathrm{F}(\mathrm{z}))$

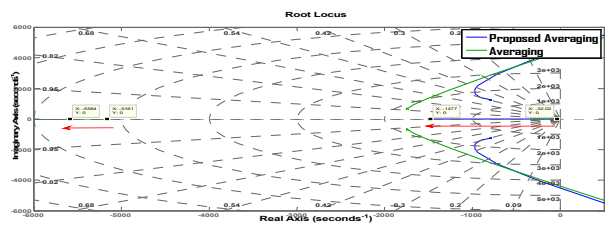

Figure 13. Root locus of the proposed and conventional closed loop averaging

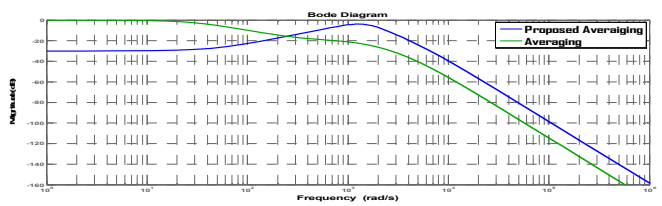

Figure 15. Gain performance to capacitor voltage disturbance under the proposed and conventional closed-loop averaging capacitor voltage controls

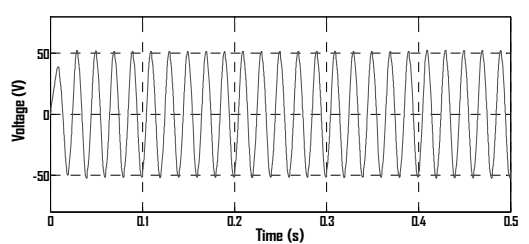

Figure 12. The MMC output AC voltage using proposed averaging control

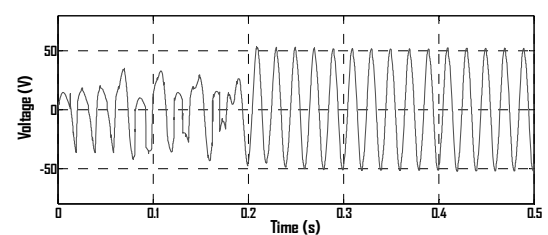

Figure 14. The MMC output AC voltage using conventional averaging control

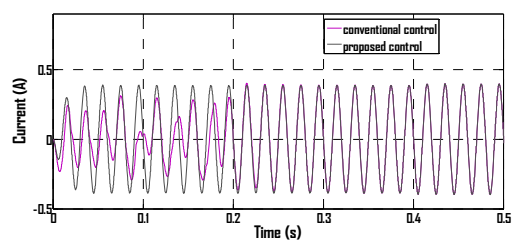

Figure 17. The MMC circulating current ( $\left.I_{c i r}\right)$ 


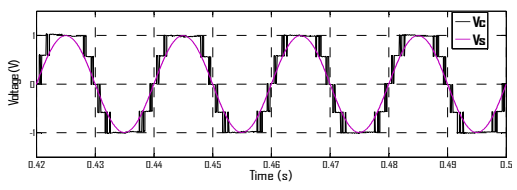

Figure 16. The MMC output AC per-phase voltage in per unit (p.u) using proposed averaging control with the grid per-phase voltage in per unit (p.u).

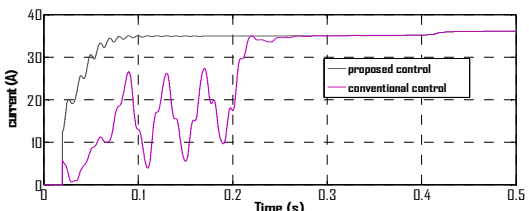

(a)

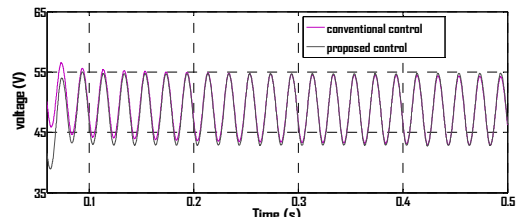

Figure 18. The MMC average capacitors voltages

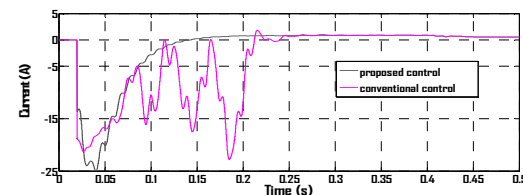

(b)

Figure 20 (a) and (b). Show the responses of the d-axis and q-axis

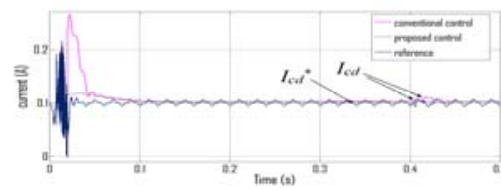

(a)

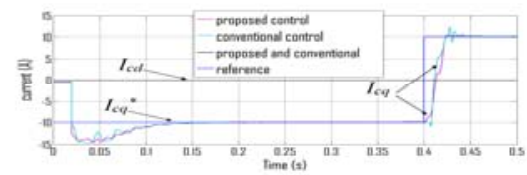

(c)

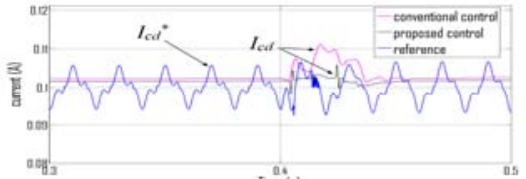

(b)

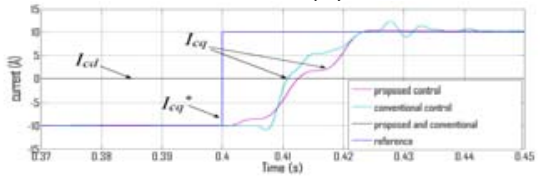

(d)

Figure 19. The MMC output (a) active current control full response (b) transition response (c) reactive current full response (b) step change response

\section{CONCLUSION}

This paper has investigated the option and simplicity of carrier-based PWM technique in enhancing the performance of vector controlled MMC for STATCOM applications. The enhancement has been achieved without the use of additional equipment or use of low switching techniques such the SHE method which has implementation complications. The suppression of the circulating current by the opposing virtual currents in the proposed scheme has enhanced the capacitor balancing, which could only be achieved when the circulating current is controlled. The introduction of the virtual impedance has served as a damping force. This feature could be used to reduce the losses in terms of harmonics in the SM capacitor cells of MMC by using a moderate switching frequency. This development has also verified that the need to reduce the number of harmonic eliminators or increasing the limit of nonlinear loads in the power system could be achieved in the MMC system for STATCOMs applications.

\section{REFERENCES}

[1] S. Du and J. Liu, "A study on de voltage control for chopper-cell-based modular multilevel converters in d-statcom application," IEEE Trans. Power Deliv, vol. 28(4), pp. 2030-2038, 2013.

[2] P. Rao, M. L. Crow, \& Z. Yang., "STATCOM control for power system voltage control applications," IEEE Trans. Power Deliv, vol. 15(4), pp. 1311-1317, 2000.

[3] K. Ilango, A. Bhargav, A. Trivikram, P. S. Kavya, G. Mounika, \& M. G. Nair., "Power Quality Improvement using STATCOM with Renewable Energy Sources," Power Electron. (IICPE), 2012 IEEE 5th India Int. Conf., p. 1-6, 2012.

[4] D. M. Reddy., "Dynamic Performance of Power Quality Improvement Using Multilevel DSTATCOM with DG Application," 2014.

Modular multilevel converter (MMC) based STATCOM with vector control... (Abdurrahman Umar Lawan) 
[5] A. U. Lawan, M. Student, H. Abbas, J. G. K. S. M, \& A. A. Karim., "Dynamic performance of Improvement of MMC Inverter with STATCOM Capability interfacing PMSG Wind Turbines with Grid," 2015 IEEE Conf. Energy Convers., pp. 492-497, 2015.

[6] A. U. Lawan, M. Mustapha, I. Abubakar, M. Mustapha, \& I. Abubakar., "Reactive current control of STATCOM based MMC Inverter for Wind Turbines connected to Grid," 2015 IEEE Student Conf. Res. Dev, pp. 26-31, 2015.

[7] L. Liu, H. Li, Y. Xue, \& W. Liu., "Reactive power compensation and optimization strategy for grid-interactive cascaded photovoltaic systems," IEEE Trans. Power Electron, vol. 30(1), pp. 188-202, 2015.

[8] H. Wang, F. Blaabjerg, \& A. East., "Reactive Power Compensation Capability of a STATCOM based on Two Types of Modular Multilevel Cascade Converters for Offshore Wind Application," pp. 326-331, 2017.

[9] A. U. Lawan, N. Magaji, \& H. Musa., "A STATCOM Controller for Small Signal Stability using Polynomial Algorithms in a Horizontal Axis Wind Farm Power System," 2013 IEEE Energytech USA, pp. 1-5, 2013.

[10] N. Magaji, A. U. Lawan, A. D. O. Dan-isa, \& M. W. Mustafa., "Design A STATCOM supplementary Controller for Stability Studies using various state feedback algorithm," Recent Res. Circuits Syst, pp. 38-43, 2012.

[11] A. U. Lawan., "State Feedback Approaches for Designing A Statcom Supplementary Controller for Oscillations Damping," Int. J. Eng. Sci, vol. 3(7), pp. 27-37, 2014.

[12] X. Wang, Y. W. Li, F. Blaabjerg, \& P. C. Loh., "Virtual-Impedance-Based Control for Voltage-Source and Current-Source Converters," IEEE Trans. Power Electron, vol. 30(12), pp. 7019-7037, 2015.

[13] G. Escobar, A. A. Valdez, R. E. Torres-Olguín, \& M. F. Martínez-Montejano., "A repetitive-based controller in stationary reference frame for D-Statcom in unbalanced operation," IEEE Int. Symp. Ind. Electron, vol. 2(2), pp. 1388-1393, 2006.

[14] L. K. Haw, M. S. A. Dahidah, S. Member, H. A. F. Almurib, \& S. Member., "A New Reactive Current Reference Algorithmfor the STATCOM System Based on Cascaded Multilevel Inverters," IEEE Trans. POWER Electron, vol. 30(7), pp. 3577-3588, 2015.

[15] H. Daniyal, E. Lam, L. J. Borle, \& H. H. C. Iu., "Hysteresis, PI and Ramptime Current Control Techniques for APF: An experimental comparison," Proc. 2011 6th IEEE Conf. Ind. Electron. Appl. ICIEA 2011, pp. 2151-2156, 2011.

[16] P. K. Jin, M. S. A. Dahidah, \& C. Klumpner., "Nine-Level SHE-PWM VSC Based STATCOM for VAR Compensation," IEEE 2010 IEEE Int. Conf. Power Energy, pp. 135-140, 2010.

[17] L. Haw, M. S. a Dahidah, \& H. a F. Almurib., "SHE-PWM Cascaded Multilevel Inverter With Adjustable DC Voltage Levels Control for STATCOM Applications," Abarrategui, O., Larruskain, D. M., Zamora, I., Valverde, V., Buigues, G., Iturregi, A. (2015). VSC- based HVDC Syst. Capab. to Ride Through Faults, (13), vol. 29(12), pp. 6433-6444, 2014.

[18] M. Miranbeigi, Y. Neyshabouri, \& H. Iman-Eini., "State feedback control strategy and voltage balancing scheme for a transformer-less STATic synchronous COMpensator based on cascaded H-bridge converter," IET Power Electron, vol. 8(6), pp. 906-917, 2015.

[19] S. Debnath, J. Qin, B. Bahrani, M. Saeedifard, \& P. Barbosa., "Operation, Control, and Applications of the Modular Multilevel Converter: A Review," IEEE Trans. Power Electron, vol. PP(99), pp. 1-1, 2014.

[20] L. Haw, M. S. a Dahidah, \& H. a F. Almurib., "SHE-PWM Cascaded Multilevel Inverter With Adjustable DC Voltage Levels Control for STATCOM Applications," Power Electron. IEEE Trans, vol. 29(12), pp. 6433-6444, 2014.

[21] M. Zhang, L. Huang, W. Yao, \& Z. Lu., "Circulating harmonic current elimination of a CPS-PWM-based modular multilevel converter with a plug-in repetitive controller," IEEE Trans. Power Electron., vol. 29(4), pp. 2083-2097, 2014.

[22] Y. Liao, S. Member, N. Chiao, \& T. Uni., "A Novel Control Strategy of Circulating Currents in Paralleled SinglePhase Boost Converters for Micro-Grid Applications Yu-Lung Ke Hung-Chi Chen Hsiu-Che Cheng," 49th IEEE/IAS Ind. Commer. Power Syst. Tech. Conf, pp. 1-9, 2013.

[23] K. Ilves, S. Norrga, L. Harnefors, \& H. P. Nee., "Analysis of arm current harmonics in modular multilevel converters with main-circuit filters," Int. Multi-Conference Syst. Signals Devices, SSD 2012 - Summ. Proc, 2012.

[24] Q. Tu, Z. Xu, H. Huang, J. Zhang, T. Qingrui, X. Zheng, H. Hongyang, \& Z. Jing., "Parameter design principle of the arm inductor in modular multilevel converter based HVDC," Power Syst. Technol. (POWERCON), 2010 Int. Conf., pp. 1-6, 2010.

[25] G. Bergna, E. Berne, P. Egrot, P. Lefranc, A. Arzande, J. C. Vannier, \& M. Molinas., "An energy-based controller for HVDC modular multilevel converter in decoupled double synchronous reference frame for voltage oscillation reduction," IEEE Trans. Ind. Electron., vol. 60(6), pp. 2360-2371, 2013.

[26] S. A. Azmi, G. P. Adam, K. H. Ahmed, S. J. Finney, \& B. W. Williams., "Grid interfacing of multimegawatt photovoltaic inverters," IEEE Trans. Power Electron., vol. 28(6), pp. 2770-2784, 2013.

[27] J. I. Y. Ota, Y. Shibano, \& H. Akagi., "A Phase-Shifted PWM D-STATCOM Using a Modular Multilevel Cascade Converter ( SSBC ) - Part II : Zero-Voltage-Ride-Through Capability," IEEE Trans. Ind. Appl, vol. 51(1), pp. 289-296, 2015.

[28] M. Hagiwara and H. Akagi, "PWM Control and Experiment of Modular Multilevel Converters," pp. 154-161, 2008.

[29] M. Hagiwara and H. Akagi, "Control and Experiment of Pulsewidth-Modulated Modular Multilevel Converters," IEEE Trans. Power Electron, vol. 24(7), pp. 1737-1746, 2009.

Int J Pow Elec \& Dri Syst Vol. 10, No. 4, Dec 2019 : 1833 - 1851 
[30] K. H. Law., "New Current Control Algorithm Incorporating Multilevel SHE-PWM Approach for STATCOM Operation under Unbalanced Condition," Power Electron. Distrib. Gener. Syst. (PEDG), 2014 IEEE 5th Int. Symp., pp. 1-7, 2014.

[31] W. L. Chen and C. Z. Xie, "Active voltage and frequency regulator design for a wind-driven induction generator to alleviate transient impacts on power grid," IEEE Trans. Ind. Electron, vol. 60(8), pp. 3165-3175, 2013.

[32] R. Lizana, S. Member, M. A. Perez, S. Member, D. Arancibia, J. R. Espinoza, \& J. Rodriguez., "Decoupled Current Model and Control of Modular Multilevel Converters," IEEE Trans. Ind. Electron., vol. 62(9), pp. 5382$5392,2015$.

[33] J. Matas, M. Castilla, L. G. De Vicuña, J. Miret, \& J. C. Vasquez., "Virtual impedance loop for droop-controlled single-phase parallel inverters using a second-order general-integrator scheme," IEEE Trans. Power Electron., vol. 25(12), pp. 2993-3002, 2010.

[34] N. Thitichaiworakorn, M. Hagiwara, \& H. Akagi., "Experimental verification of a modular multilevel cascade inverter based on double-star bridge cells," IEEE Trans. Ind. Appl, vol. 50(1), pp. 509-519, 2014.

[35] M. Hagiwara, R. Maeda, \& H. Akagi., "Control and analysis of the modular multilevel cascade converter based on double-star chopper-cells (MMCC-DSCC)," IEEE Trans. Power Electron, vol. 26(6), pp. 1649-1658, 2011.

[36] K. Lee, T. M. Jahns, T. A. Lipo, \& V. Blasko., "New control method including state observer of voltage unbalance for grid voltage-source converters," IEEE Trans. Ind. Electron., vol. 57(6), pp. 2054-2065, 2010.

[37] AU Lawan, HAF Almurib, JG Khor, \& S Babani., "Circulating Current control of a Modular Multilevel Converter (MMC) with State Feedback Controller and Harmonic Current Suppression," 2018 IEEE International Conference on Electrical Systems for Aircraft, Railway, Ship Propulsion and Road Vehicles \& International Transportation Electrification Conference (ESARS-ITEC), pp. 1-8, 2018.

[38] Syed Zulqadar Hassan, Hui Li, Tariq Kamal, Ali Arsalan, \& Abdurrahman Umar Lawan., "Performance of gridintegrated Wind/Microturbine/battery Hybrid renewable power system," Power and Energy (PECon), 2016 IEEE International Conference, pp. 78-83, 2016.

[39] Abubakar Abdulkarim, Sobhy Mohammed Abdelkader, D John Morrow, Falade John Alaba, Abdurrahman Umar Lawan, \& HR Iswadi., "Effect of weather and the hybrid energy storage on the availability of standalone microgrid," International Journal of Renewable Energy Research (IJRER), vol. 6(1), pp. 189-198, 2016.

[40] Abdurrahman Umar Lawan, Haider A.F. Almurib, \& Jeen G. Khor., "Enhanced decoupled Current Control with Voltage Compensation for Modular Multilevel Converter (MMC) based STATCOM," International Journal of Power Electronics and Drives System (IJPEDS), vol. 10(3), pp. 24-25, 2019. 